\title{
PENGARUH DUKUNGAN KELUARGA TERHADAP SIKAP KEPALA KELUARGA TENTANG PENYAKIT FILARIASIS DI RW 02 KAMPUNG DUSUN PUSAKA KECAMATAN PUSAKO KABUPATEN SIAK
}

\author{
Rifa Yanti ${ }^{1}$, Fitra Mayenti ${ }^{2}$ \\ ${ }^{1,2}$ Staf Dosen STIKes Al-Insyirah Pekanbaru \\ E-mail : rifaye1@ymail.com
}

Diterima : Agustus 2018, Diterbitkan : Desember 2018

\begin{abstract}
Abstrak
Latar Belakang : Filariasis salah satu jenis penyakit yang mendapat perhatian khusus di dunia kesehatan, lebih dari 1(satu) miliar penduduk dunia memiliki risiko menderita filariasis dan lebih dari 120 juta orang dari 80 negara telah terinfeksi filariasis. WHO (World Health Organization) mencanangkan kesepakatan global untuk memberantas penyakit filariasis dengan The Global Goal of Elimination of Lymphatic Filariasis as Public Health Problem by the Year $2020 \quad$ (WHO, 2010). Pada tahun 2003, penyakit filariasis di Indonesia dilaporkan sebanyak 6.571 kasus. Pada tahun 2007 dijumpai 11.473 kasus dan pada tahun 2008 terdapat 11.699 kasus kemudian meningkat menjadi 11.914 kasus pada tahun 2009. Hampir ribuan desa di 26 provinsi di Indonesia dinyatakan endemis. (Kemenkes RI, 2010). Tujuan penelitian ini mengetahui pengaruh dukungan keluarga dengan sikap kepala keluarga tentang penyakit filariasis di RW 02 Kampung Dusun Pusaka Kecamatan Pusako Kabupaten Siak. Metode penelitian kuantitatif observational dengan pendekatan cross sectional. Pengumpulan data dilakukan dengan cara menyebarkan angket dan dianalisis secara univariat dan bivariat. Hasil penelitian didapatkan dari 116 repsonden, $62.1 \%$ dukungan keluarga baik dan 37.9\% dukungan keluarga kurang baik, dan sikap kepala keluarga 60,3\% positif dan $39,7 \%$ sikap responden negatif. Hasil uji statistik didapatkan ada pengaruh yang signifikan antara dukungan keluarga dengan sikap kepala keluarga tentang penyakit filariasis ( $p$.Value $=0,00$ ). Diharapkan kepada petugas kesehatan agar lebih aktif menggiatkan serta memberikan penyuluhan tentang penyakit filariasis khususnya di RW 02.
\end{abstract}

Kata Kunci : Dukungan keluarga, sikap kepala keluarga, penyakit filariasis

\begin{abstract}
Background: Filariasis is one of the most commonly recognized diseases in the world of health, more than 1 billion of the world's population at risk of filariasis and more than 120 million people from 80 countries had been infected with filariasis. WHO (World Health Organization) had launched a global agreement to eradicate filariasis with The Global Goal of Elimination of Lymphatic Filariasis by Health Health Problem by the Year 2020 (WHO, 2010). In 2003, filariasis disease in Indonesia was reported as many as 6,571 cases. In 2007 there were 11,473 cases and in 2008 there were 11,699 cases then increased to 11,914 cases in 2009. Nearly thousands of villages in 26 provinces in Indonesia were declared endemic (Health Ministry of Indonesia, 2010). The purpose of this study was to know the effect of family support with the attitude of the head of the family about filariasis disease in RW 02 Kampung Dusun Pusaka Kecamatan Pusako Siak District. Quantitative observational research method with cross sectional approach. Data collection was done by distributing questionnaires and analyzed univariat and bivariate. Results of the study were 116 respondents, $62.1 \%$ good family support and $37.9 \%$ poor family support, and attitude of family head 60,3\% positive and 39,7\% respondent attitude negatiif. The result of statistical test showed that there was significant influence between family support and family head attitude about filariasis disease (p.Value = 0,00). it is expected to the health officer to be more actively activate and give counseling about filariasis disease specially in $R W 02$.
\end{abstract}

Keywords: Family support, family head attitude, filariasis disease 


\section{LATAR BELAKANG}

Filariasis salah satu jenis penyakit yang mendapat perhatian khusus di dunia kesehatan. Walaupun jarang menyebabkan kematian, pada stadium lanjut dapat menyebabkan cacat fisik permanen hingga menimbulkan dampak yang signifikan, terutama di daerah tropis maupun sub tropis yang mengalami permasalahan sosial ekonomi. Lebih dari 1 miliar penduduk dunia memiliki risiko menderita filariasis, Lebih dari 120 juta orang dari 80 negara telah terinfeksi filariasis. WHO (World Health Organization) mencanangkan kesepakatan global untuk memberantas penyakit filariasis dengan The Global Goal of Elimination of Lymphatic Filariasis as Public HealthProblem by the Year 2020 (WHO, 2010).

Sekitar 1,3 milyar penduduk di dunia pada tahun 2009 berada di negara beresiko tertular filariasis yang tersebar diberbagai wilayah. Wilayah yang memiliki negara endemis terbanyak adalah benua Afrika dimana terdapat 39 negara endemis dengan populasi berisiko 396 juta orang disusul oleh Amerika yang mana terdapat 7 negara endemis dengan 12 juta orang beresiko, selanjutnya wilayah bagian timur Mediterania 3 negara endemis dengan 12 juta orang berisiko. Wilayah Asia Tenggara sekitar $66 \%$ dari populasi global berisiko filariasis dimana 426 juta orang sudah menerima perawatan di 9 Negara endemis termasuk salah satunya Indonesia (WHO, 2010).

Pada tahun 2003, penyakit filariasis di Indonesia dilaporkan sebanyak 6.571 kasus. Pada tahun 2007 dijumpai 11.473 kasus dan pada tahun 2008 terdapat 11.699 kasus kemudian meningkat menjadi 11.914 kasus pada tahun 2009. Hampir ribuan desa di 26 provinsi di Indonesia dinyatakan endemis. (Kemenkes RI, 2010).

Penyakit Filariasis ditemukan hampir di seluruh wilayah Indonesia seperti di Sumatera, Jawa, Kalimantan, Sulawesi,
Nusa Tenggara, dan Papua, baik perkotaan maupun pedesaan. Kasus di pedesaan banyak ditemukan di kawasan Indonesia bagian timur, sedangkan untuk di perkotaan banyak ditemukan di daerah seperti, Bekasi, Tangerang, Pekalongan, dan Lebak (Banten). Berdasarkan hasil survei cepat tahun 2000, jumlah penderita kronis yang dilaporkan sebanyak 6.233 orang tersebar di 1.553 desa, di 231 Kabupaten, 26 Provinsi (Depkes RI, 2006).

Data ini belum menggambarkan keadaan yang sebenarnya karena hanya dilaporkan oleh 42\% Puskesmas dari 7.221 Puskesmas. Tingkat endemisitas filariasis di Indonesia berdasarkan hasil survei darah jari tahun 1999 masih tinggi dengan microfilaria $(M f)$ rate 3,1\% (0,5-19,64\%). Berdasarkan survei untuk pemeriksan mikroskopis pada desa dengan jumlah penderita terbanyak pada tahun 2002-2005, terutama di Sumatera dan Kalimantan, telah teridentifikasi 84 Kabupaten atau Kota dengan microfilaria rate $1 \%$ atau lebih. Data tersebut menggambarkan bahwa seluruh daerah di Sumatera dan Kalimantan merupakan daerah endemis filariasis (Nasry, 2006).Tahun 2004 di Indonesia diperkirakan 6 juta orang terinfeksi filariasis dan dilaporkan lebih dari 8.000 orang di antaranya menderita kronis filariasis terutama di pedesaan (Depkes RI, 2006).

Upaya penemuan penderita filariasis tahun 2004 di Indonesia diperkirakan 6 juta orang terinfeksi filariasis dan dilaporkan lebih dari 8.000 orang diantaranya menderita kronis filariasis terutama di pedesaan. Kriteria kabupaten atau kota endemis filaria bila Mf Rate (microfilaria) $1 \%$ disalah satu atau lebih lokasi survei maka kabupaten atau kota tersebut ditetapkan sebagai daerah endemis yang harus dilaksanakan pengobatan massal. Bila $M f$ rate (microfilaria) $<1 \%$ pada semua lokasi survei, maka kabupaten atau kota tersebut ditetapkan sebagai daerah non endemis dan dilaksanakan pengobatan selektif, yaitu 
pengobatan hanya diberikan pada penderita yang positif mikrofilaria beserta anggota keluarganya. Penetapan kabupaten atau kota endemis filariasis dilakukan berdasarkan hasil survei dan survei darah jari, dan ditetapkan oleh Provinsi (Depkes RI,2006).

Menteri Kesehatan Republik Indonesia telah mencanangkan dimulainya eliminasi penyakit kaki gajah di Indonesia dan telah menetapkan eliminasi kaki gajah sebagai salah satu program prioritas. Pedoman pengendalian penyakit filariasis tertuang dalam Keputusan Menteri Kesehatan Republik Indonesia Nomor: 1582/MENKES/SK/XI/2005 tanggal 18 November 2005 (Kemenkes RI, 2010).

Angka kesakitan filariasis yang ada di Provinsi Riau pada bulan Oktober 2015 terbesar di beberapa kabupaten. Kabupaten Siak merupakan kabupaten yang memiliki angka kesakitan Nomor 4 terbesar di Provinsi Riau setelah Kabupaten Meranti, Kabupaten Indragiru Hulu dan Kabupaten Indragiri Hilir (Dinkes Prov. Riau, 2015). Kecamatan Pusako memiliki kejadian penyakit filariasis berjumlah 6 kasus (Dinkes Kabupaten Siak, 2015). Penelitian dilakukan di Dusun pusaka di RW 02 dengan jumlah kepala keluarga yang ada di RW 02 Kampung Dusun Pusaka Kecamatan Pusako berjumlah 163 kepala keluarga, di RT 01 berjumlah 68 kepala keluarga dan RT 02 berjumlah 95 kepala keluarga. Seiring meningkatnya angka kejadian penyakit filariasis maka peran serta dukungan dari keluarga sangat diperlukan dalam hal pencegahan penyakit filariasis.

Beberapa penelitian terkait faktor yang mempengaruhi penyakit filariasis, penelitian yang Santoso di kabupaten Tanjung Jabung Timur (2014) melaporkan bahwa 30 sikap responden dengan $37,6 \%$ kategori kurang baik tentang filariasis dan penelitian Candriana Yanuarini di puskesmas Tirto I kabupaten Pekalongan $40,9 \%$ sikap responden negatf tentang penyakit filariasis.

\section{METODE PENELITIAN}

Metode yang dilakukan dalam penelitian ini adalah kuantitatif observational dengan pendekatan cross sectional dimana variabel penelitian diukur atau dikumpulkan dalam satu waktu, artinya pengamatan hanya sekali terhadap beberapa variabel dalam waktu bersamaan

\section{HASIL DAN PEMBAHASAN}

Tabel Distribusi Frekuensi Karakteristik Responden di di RW 02 Kampung Dusun Pusaka Kecamatan Pusako Kabupaten Siak

\begin{tabular}{cccc}
\hline $\begin{array}{c}\text { Karakteristik } \\
\text { Responden }\end{array}$ & Kategori & f & \% \\
\hline 1. Pendidikan & PT & 2 & 1.7 \\
Responden & SMA & 37 & 37 \\
& SMP & 24 & 20.7 \\
& SD & 53 & 45.7 \\
2. Jenis & Laki-laki & 106 & 91.4 \\
Kelamin & Perempuan & 10 & 8.6 \\
3. Pekerjaan & PNS & 3 & 2.6 \\
Responden & Non PNS & 113 & 97.4 \\
\hline
\end{tabular}

Tahun 2017

Berdasarkan tabel 4.1 menunjukkan dari 116 responden, pendidikan responden $45.7 \%$ pendidikan $\mathrm{SD}, 37 \%$ pendidikan SMA, $20.7 \%$ pendidikan SMP dan 1.7 pendidikan Perguruan Tinggi. Jenis kelamin responden $91.4 \%$ berjenis kelamin laki-laki dan $8.6 \%$ berjenis kelamin perempuan sedangkan pekerjaan responden 97.4\% Non PNS dan 2.6\% PNS.

Tabel Dukungan Keluarga di RW 02

\begin{tabular}{llcc}
\hline No & $\begin{array}{c}\text { Dukungan } \\
\text { Keluarga }\end{array}$ & f & \% \\
\hline 1. & Kurang Baik & 44 & 37.9 \\
2. & Baik & 72 & 62.1 \\
& Total & $\mathbf{1 1 6}$ & $\mathbf{1 0 0}$ \\
\hline
\end{tabular}

Kampung Dusun Pusaka Kecamatan Pusako Kabupaten Siak

Berdasarkan tabel diatas menunjukkan dari 116 responden $62.1 \%$ dukungan keluarga baik dan $37.9 \%$ dukungan keluarga kurang baik. Hasil penelitian ini sesuai dengan 
penelitian Kadiatun, T di Rasau Jaya II Kabupaten Kubu Raya (2016) melaporkan bahwasanya $60.2 \%$ dukungan keluarga baik dan 39.8\% dukungan keluarga kurang baik. Keluarga merupakan unit terkecil dalam suatu masyarakat yang sangan berperan dalam perawatan keluarga yang sakit, terutama anggota keluarga yang menderita filariasis, karena itu dukungan keluarga yang baik akan membantu dalam pencegahan dan penanggulangan penyakit filariasis.

Hasil penelitian ini berbeda dengan penelitian Tutur Kardiatun di Rasau Jaya II Kabupaten Kubu Raya (2016), melaporkan bahwa Dukungan Keluarga baik 60,2 \%, dukungan yang kurang baik 39,8\% tentang pencegahan penyakit filariasis. Menurut Ali, Zainudi (2006) dukungan keluarga merupakan tindakan dan penerimaan suatu keadaan yang bermanfaat bagi individu yang diperoleh dari orang lain yang dipercaya, sehingga seseorang akan tahu bahwa ada orang lain yang memperhatikan, menghargai dan mencintainya.

Tabel Distribusi Frekuensi Sikap responden tentang penyakit filariasis di RW 02 Kampung Dusun Pusaka Kecamatan Pusako Kabupaten Siak Tahun 2017

\begin{tabular}{cccc} 
No & Sikap & f & $\mathbf{\%}$ \\
\hline 1. & Negatif & 46 & 39.7 \\
2. & Positif & 70 & 60.3 \\
\hline & Total & $\mathbf{1 1 6}$ & $\mathbf{1 0 0}$ \\
\hline
\end{tabular}

Tabel diatas menunjukkan dari 116 responden $60,3 \%$ sikap responden positif dan $39,7 \%$ sikap responden negatif. Sikap merupakan respon tertutup sesorang terhadap stimulus atau objek tertentu yang sudah melibatkan faktor emosi seseorang yang bersangkutan (senang - tidak senang, setuju - tidak setuju, baik - tidak baik). Sikap merupakan salah satu bentuk prilaku individu, yang mempengaruhi individu dalam melakukan tindakan, sikap responden yang positif terhadap anggota keluarga yang menderita filariasis akan membantu mengurangi atau pencegahan terhadap penyakit filariasis, sehingga responden berupaya terus untuk menjaga lingkungan tempat tinggalnya akan tidak tercemar dan tertular penyakit filariasis.

Menurut Teori Green yang menyatakan bahwa sikap adalah satu predisposisi untuk munculnya perilaku dapat dibuktikan dalam penelitian ini. Hal ini juga sesuai dengan pernyataan Notoatmodjo (1993) yang dikutip oleh penelitian Sari (2006), menyatakan bahwa perilaku seseorang akan dipengaruhi oleh kepercayaan, kehidupan emosional, dan kecenderungan untuk berperilaku yang semua itu merupakan komponen sikap.

Tabel Pengaruh Dukungan Keluarga terhadap Sikap Kepala Keluarga Tentang Penyakit Filariasis di RW 02 Kampung Dusun Pusaka Kecamatan Pusako Kabupaten Siak Pekanbaru Tahun 2017 $(\mathrm{n}=116)$

\begin{tabular}{|c|c|c|c|c|c|c|c|c|}
\hline \multirow{3}{*}{$\begin{array}{l}\mathbf{N} \\
\mathbf{O}\end{array}$} & \multirow{3}{*}{$\begin{array}{c}\text { Dukung } \\
\text { an } \\
\text { Keluarg } \\
\text { a }\end{array}$} & \multicolumn{4}{|c|}{$\begin{array}{c}\text { Sikap Kepala } \\
\text { Keluarga }\end{array}$} & \multirow{2}{*}{\multicolumn{2}{|c|}{ Total }} & \multirow{2}{*}{$\begin{array}{l}\text { p. } \\
\text { Va } \\
\text { lue }\end{array}$} \\
\hline & & \multicolumn{2}{|c|}{ Negatif } & \multicolumn{2}{|c|}{ Positif } & & & \\
\hline & & $\mathbf{f}$ & $\%$ & $\mathbf{f}$ & $\%$ & $\mathbf{f}$ & $\%$ & \\
\hline 1. & Kurang & 43 & 97. & 1 & 2.3 & 44 & 10 & \\
\hline & Baik & & 7 & & & & 0 & \\
\hline 2. & Baik & 3 & 4.2 & 69 & $\begin{array}{c}95 . \\
8\end{array}$ & 69 & $\begin{array}{c}10 \\
0\end{array}$ & 0 \\
\hline & Total & 46 & & 70 & & $\begin{array}{c}11 \\
6\end{array}$ & $\begin{array}{c}10 \\
0\end{array}$ & \\
\hline
\end{tabular}

Berdasarkan tabel diatas menunjukkan presentasi sikap kepala keluarga yang negatif lebih tinggi pada dukungan keluarga kurang baik dibandingkan dengan yang baik (97.7\%:4.2\%) sedangkan presentasi sikap kepala keluarga positif dukungan keluarga baik lebih tinggi dibandingkan dengan yang kurang baik $(2.3 \%: 95.8 \%)$.

Hasil uji statistik didapatkan nilai $p$ Value= $0,00<0.05$ artinya ada pengaruh yang signifikan antara dukungan keluarga 
dengan sikap kepala keluarga tentang penyakit filariasis di RW 02 Kampung Pusaka Kecamatan Pusako Kabupaten Siak Pekanbaru.

Penelitian ini senada dengan penelitian Kadiatun, T di Rasau Jaya II Kabupaten Kubu Raya (2016) didapatkan ada hubungan yang signifikan antara dukungan keluarga dengan pencegahan filariasis. Menurut Ali, Z (2006), dukungan keluarga menjadikan keluarga berfungsi dengan berbagai kepandaian dan akal, sehingga dapat meningkatkan kesehatan dan adaptasi mereka dalam kehidupannya karena dukungan sosial dari keluarga mempunyai efek yang sangat penting bagi kesehatan dan kesejahteraan berfungsi bersamaan, dengan adanya dukungan akan memberikan rasa kepercayaan diri untuk menghadapi masalah seperti sedang dalam keadaan sakit. Keluarga yang peduli akan kesehatan anggota keluarganya yang sedang sakit maka ia kan memperhatikan dan mengupayakan apapun demi kesembuhan anggota keluarganya yang sedang sakit seperti mengupayakan dana untuk pengobatan, fasilitas yang diperlukan untuk pengobatan, fasilitas yang diperlukan demi kesembuhannya, menghargai dan saling memaklumi serta memberi pujian yang positif serta mencari informasi demi perkembangan dan kesembuhannya.

Peneliti berasumsi bahwa masih ditemukan $2.3 \%$ sikap kepala keluarga positif, namun dukungan keluarga masih kurang baik hal ini dapat disebabkan oleh beberapa faktor, diantaranya komunikasi didalam keluarga belum terbangun secara kondusif dikarenakan kesibukan melakukan pekerjaan sehari-hari untuk memenuhi kebutuhan hidup, pertemuan antar keluarga hanya dilakukan pada malam hari, dan juga disebabkan oleh masih rendahnya tingkat pendidikan kepala keluarga, dalam penelitian ini rata-rata responden berpendidikan sekolah dasar.

\section{Saran}

1. Diharapkan kepala keluarga untuk dapat meningkatkan kepeduliannya terhadap anggota keluarga terhadap penyakit Filariasis

2. Diharapkan petugas kesehatan agar lebih aktif menggiatkan serta memberikan penyuluhan tentang penyakit filariasis khususnya di RW 02.

3. Diharapkan penelitian ini mejadi referensi bagi peneliti selanjutnya dalam mengembangkan penelitian filariasis dengan varibel yang berbeda dan lebih banyak lagi.

\section{DAFTAR PUSTAKA}

Ali, Zainudin, 2006. Pengantar keperawatan keluarga. Jakarta : EGC

Ansyari. 2004. Faktor risiko kejadian filariasis di desa tanjung Bayur Pontianak.

Astri. 2006, Studi faktor risiko filariasis di desa Sambirejo, Kecamatan Tirto Kabupaten Pekalongan Jawa tengah. Rinbinkes. BPVRP-Salatiga.

Chin, J. 2006, Manual Pemberantasan Penyakit Menular. Edisi 17, Cetakan II. Editor : dr. I. Nyoman Kandun. Jakarta : CV Infomedika.

Depkes RI, 2005. Pedoman Penentuan Dan Evaluasi Daerah Endemis Filariasis. Jakarta : Ditjen PP \& PL

2006.Pedoman

Penatalaksanaan Kasus Klinis Filariasis. Jakarta : Ditjen PP \& PL. , 2007. Pedoman Promosi Kesehatan Dalam Eliminasi Filariasis.Jakarta : Ditjen PP \& PL.

Dinas Kesehatan Kabupaten Siak, 2015.Data penemuan penyakit filariasis.Siak: Dinkes Kabupaten Siak

Dinas Kesehatan Provinsi Riau, 2015. Data penemuan penyakit filariasis.Pekanbaru:DinkesProvinsi Riau

Kementerian Kesehatan Republik Indonesia, Ditjen PP \& PL Direktorat P2B2 Subdit Filariasis \& Schistomiasis. (2010). Rencan 
a nasional program akselerasi eliminasi filariasis di Indonesia 2010-2014. http://pppl.depkes.go.id/_asset/_down load/national plan filariasis 2010ind 2010-14.pdf. Diakses tanggal 22 Desember 2015

Kadarusman, 2003.Faktor- faktor yang berhubungan dengan kejadian filariasis di desatalang Babat Kecamatan Muara Sabak Kabupaten Tanjung Jabung Timur Propinsi Jambi. FKM-UI.

Kardiatun, Tutur, 2016. Hubungan dukungan keluarga dengan pencegahan filariasis di Rasau Jaya II Kabuaten Kubu Raya. Jurnal Keperawatan dan Kesehatan Vol.VII. No.1 (56-65)

Nasry, 2006. Pengantar Epidemiologi Penyakit Menular. Rineka Cipta : Jakarta

Notoatmodjo, Soekidjo, 2003. Pendidikan dan Perilaku Kesehatan. Jakarta : Rineka Cipta

\footnotetext{
, 2005. Ilmu Kesehatan Masyarakat. Jakarta : P.T.Rineka Cipta.
}

\section{Promosi}

Kesehatan dan Perilaku Kesehatan.. Jakarta : Rineka Cipta.

Santoso, 2014.Pengaruh promosi kesehatan terhadap pengetahuan, sikap dan perilaku masyrakat tentang filariasis di kabupaten Tanjung Jabung Timur.

Vol. 41, No. 3, 2014:152-162

Soedarto, 2012. Penyakit-Penyakit Infeksi Di Indonesia. Jakarta : Widya medika

Wawan, A. 2011. Teori dan Pengukuran Pengetahuan, Sikap dan Perilaku Manusia. Yogyakarta : Mutia Medika.

Yanuarini, Candriana, 2015. Faktor-faktor yang berhubungan dengan kejadian filariasis di puskesmas Tirto I kabupaten Pekalongan. FIKKES, No.1, 73-86

World Health Organization, 2010 . Newsletter Action Against Worms, ISSUE

http://www.healthinternetwork.com/ne glected_diseases/preventive_chemothe
rapy/Newsletter14_En.pdf._Diakses tanggal 14 Februari 2016

Zuriah, 2003. Penelitian Tindakan Dalam Bidang Pendidikan dan Sosial. Malang : Banyu Publishing 